\title{
Photo-temperature response of ramie (Boehmeria nivea (L.) Gaud.) male sterile lines
}

\author{
Fei-Hu Liu ${ }^{1^{*}}$, Hai-Quan Huang ${ }^{1,2}$, Shou-Wen Zhang $^{3}$, Xue-Ni Liang ${ }^{1}$ \\ ${ }^{1}$ Plant Improvement and Utilization Laboratory,Yunnan University, Kunming, China; \\ *Corresponding Author: hnplantbreed@gmail.com \\ ${ }^{2}$ College of Landscape Architecture, Southwest Forestry University, Kunming, China; \\ ${ }^{3}$ Department of Pharmacy, Jiangxi University of Traditional Chinese Medicine, Nanchang, China;
}

Received 3 February 2011; revised 2 March 2011; accepted 31 March 2011.

\begin{abstract}
Six male sterile lines (MSLs) of ramie (Boehmeria nivea (L.) Gaud.) were grown in dark rooms under the photoperiods of $9.5 \mathrm{~h}, 11 \mathrm{~h}$ or $12.5 \mathrm{~h}$ $\mathrm{d}^{-1}$ in spring and summer seasons (different environmental temperatures) to test their developmental response to photoperiod and temperature. The MSLs showed little difference in vegetative growth duration, but different development rates in the reproductive growth stage under the tested conditions. Higher temperature (grown in summer) mainly accelerated vegetative growth, while the short photoperiod treatment accelerated the reproductive growth of the MSLs. Moreover, the short photoperiod treatment combined with higher temperature obviously accelerated both the vegetative and reproductive growth of the MSLs. But the effect of higher temperature decreased, or even disappeared along with the photoperiod elongation. The MSLs were divided into 5 photo-temperature response types, based on the flower budding acceleration of short photoperiod and the approximate temperature response index.
\end{abstract}

Keywords: Flower Budding Acceleration; Photoperiod Sensitivity; Ramie (Boehmeria Nivea

(L.) Gaud.); Temperature Response Index

\section{INTRODUCTION}

Male sterility exists in many plant species [1]. The discovery of plant male sterility allowed the use of crop heterosis, resulting in great achievements in crops such as corn, rice, wheat, rape and many vegetables $[1,2]$.

Ramie, mainly grown in China, the Philippines, Brazil, India and Viet Nam, is one of the most popular textile fiber plants. Ramie fabrics are becoming popular all over the world owing the mode of "back to the nature", which is leading the ramie industry into a new development era. Ramie male sterile plants were found amongst local cultivars in the 1960's [3]. Male sterility can also be produced by chemical induction [4]. Although some progress has been made in the biochemical and physiological traits of ramie male sterile lines [5,6] and in the utilization of ramie male sterile heterosis [7,8], a lack of understanding of the photo-temperature responses of male sterile lines (MSLs) has impeded further advancements in ramie male sterility utilization. Therefore, we investigated the development of ramie MSLs under different photoperiods and temperatures (grown in different seasons), with a view to characterizing their response to photoperiod and temperature. This information will provide guidance for determining cross combinations, assist with the breeding of new cultivars and assist with ramie seed production generally.

\section{MATERIALS AND METHOD}

The tested ramie male sterile lines (MSLs) GS13-942, GSA-2, SS370, GS14-4, GS14-1 and GS15-8, obtained via chemical induction from a local cultivar (Liang et al. 1998), were planted in $25 \times 35 \mathrm{~cm}$ pots under normal management. The MSLs were treated under 9.5, 11 and $12.5 \mathrm{~h} \cdot \mathrm{d}^{-1}$ photoperiods of daylight (natural light), respectively in the spring and in the summer, by putting them into dark rooms in late afternoon and getting out of dark rooms in the morning, when the plants grew up to $30 \mathrm{~cm}$ tall (30 days old in the spring and 15 days old in the summer). Pot cultured MSLs, grown under the natural conditions were used as the controls. Five replicate pots of each line were used for each photoperiod treatment. Dark room treatment terminated once pistillate flowers had blossomed. Some MSLs had no staminate flowers, so the openings of pistillate flowers (stigma emergence) were recorded. Daily outside temperature data were collected during the period of experiment. 
The developmental acceleration (DA, \%) as a result of a short photoperiod (or a high temperature) treatment was calculated as $[(A-B) / A] \times 100$ [9], where $A$ was the growth duration under the long photoperiod (i.e. $12.5 \mathrm{~h}$ $\mathrm{d}^{-1}$, in this experiment), or under low temperature (in the spring, in this experiment) and $B$ the growth duration under the short photoperiod (i.e. $9.5 \mathrm{~h} \cdot \mathrm{d}^{-1}$ ), or high temperature (in the summer). Similarly, the flower budding acceleration (FBA, \%) of a short photoperiod treatment was calculated as $[(N-M) / N] \times 100$ [10], where $N$ was the number of days from shoot emergence to flower budding for the controls, and $M$ represented the number of days from shoot emergence to flower budding under the short photoperiod. An approximate temperature response index (TRI) was calculated as $(L-H) /\left(T_{h}-T_{l}\right)$ [10], where $L$ was the number of days from shoot emergence to flower budding under the low temperature conditions (in the spring for this experiment), $H$ was the number of days from shoot emergence to flower budding under the high temperature conditions (in the summer), $T_{h}$ represented the mean temperature during the summer treatment period, and $T_{l}$ was the mean temperature during the spring treatment period. Statistical analyses were done with Statistica 5.

\section{RESULTS}

\subsection{Development Rates of the MSLs under Short Photoperiod in Different Seasons}

The vegetative growth stage, the number of days from shoot emergence to pistillate budding, showed no evident difference for the spring treatment, but different for the summer treatment among the tested MSLs (Table 1).
The MSLs had significant differences in their reproducetive growth duration, the number of days from pistillate budding to pistillate flower blooming, both for the spring or summer treatments. In addition, under the same short photoperiod condition $\left(9.5 \mathrm{~h} \cdot \mathrm{d}^{-1}\right)$, the MSLs had a much shorter vegetative growth duration in the summer than in the spring (Table 1, column average). Therefore, it is important to adjust the development schedule to meet the parents' flowering time when the MSLs are used in cross breeding.

\subsection{High Temperature Accelerates the Development of Ramie MSLs Mainly in the Vegetative Growth Periods}

Under the suitable temperatures for ramie growth and under a given photoperiod, higher environmental temperature (summer treatment) accelerated the development of the MSLs, resulting in a reduction of growth duration (Table 2). This confirmed the sensitivity of the MSLs to temperature. The development accelerations in the summer indicated that the high temperature increased the development rate more for the vegetative growth stage than for the reproductive growth stage (Table 2). Here the period from shoot emergence (SE) to pistillate budding $(\mathrm{PB})$ is the vegetative growth duration, while the period from pistillate budding $(\mathrm{PB})$ to pistillate flower blooming (PFB) is the reproductive growth duration.

Among the MSLs, GS13-942 and GS14-1 were highly sensitive to season change (maybe mainly the effect of temperature), showing the approximate temperature re-

Table 1. Development duration of ramie MSLs under $9.5 \mathrm{~h} \cdot \mathrm{d}^{-1}$ photoperiod.

\begin{tabular}{|c|c|c|c|c|c|c|c|c|c|c|}
\hline \multirow{2}{*}{$\begin{array}{l}\text { Growth } \\
\text { period }\end{array}$} & \multirow{2}{*}{ Seasons } & \multirow{2}{*}{$\begin{array}{c}\text { Daily mean } \\
\text { temperature }\left({ }^{\circ} \mathrm{C}\right)\end{array}$} & \multicolumn{6}{|c|}{ Developmental duration of MSLs (d) $\dagger$} & \multirow{2}{*}{$\begin{array}{l}\text { Aver- } \\
\text { ageł }\end{array}$} & \multirow{2}{*}{ P-value } \\
\hline & & & GS13-942 & GSA-2 & GS15-8 & SS370 & GS14-4 & GS14-1 & & \\
\hline \multirow{2}{*}{ SE-PB } & Spring & 23.0 & 39a & 39a & 39a & $39 a$ & $40 \mathrm{a}$ & 39a & 39a & 0.000 \\
\hline & Summer & 29.4 & $18 \mathrm{c}$ & $20 \mathrm{~b}$ & $22 a$ & $22 a$ & $23 a$ & $20 \mathrm{~b}$ & $21 b$ & 0.000 \\
\hline \multirow{2}{*}{ PB-PFB } & Spring & 24.4 & $22 a$ & $22 \mathrm{a}$ & $17 \mathrm{~b}$ & $18 \mathrm{~b}$ & $21 \mathrm{a}$ & $17 \mathrm{~b}$ & $19 a$ & 0.062 \\
\hline & Summer & 30.8 & $20 \mathrm{a}$ & $17 \mathrm{~b}$ & $17 \mathrm{~b}$ & $16 \mathrm{~b}$ & $17 \mathrm{~b}$ & $14 \mathrm{c}$ & $17 a$ & 0.062 \\
\hline
\end{tabular}

SE — shoot emergence; PB—pistillate budding; PFB—pistillate flower blooming; †Followed by the same letter are not significantly different at $\mathrm{P}=0.05$ among the MSLs by LSD test; $\ddagger$ Comparison of summer vs spring within each growth period at $\mathrm{P}=0.05$ by T-test.

Table 2. Effect of season (temperature) on the development of MSLs under $9.5 \mathrm{~h} \cdot \mathrm{d}^{-1}$ photoperiod.

\begin{tabular}{ccccccc}
\hline \multirow{2}{*}{ Growth period } & \multicolumn{2}{c}{ Duration $(\mathrm{d} \pm \mathrm{SD})$} & & Daily mean temp in the period $\left({ }^{\circ} \mathrm{C}\right)$ & \multicolumn{2}{c}{$\begin{array}{c}\text { DA of high } \\
\text { temperature }(\%)\end{array}$} \\
\cline { 2 - 3 } & Spring & Summer & & Spring & Summer & \\
SE-PB & $39 \pm 0.4$ & $21 \pm 1.8$ & & 23 & 29 & 37 \\
SE-PFB & $59 \pm 3.5$ & $38 \pm 3.1$ & & 24 & 30 & 35 \\
PB-PFB & $19 \pm 2.4$ & $17 \pm 1.9$ & & 24 & 31 & 12 \\
\hline
\end{tabular}

SE-Shoot emergence; PB_-Pistillate budding; PFB—Pistillate flower blooming; DA—Developmental acceleration. 
sponse indices (TRI) over 3. GS15-8 and SS370 were not very sensitive to season change, the TRIs were 2.5 or below. GSA-2 and GS14-4 showed moderate sensitivity to season change (Table 3 ).

\subsection{Short Photoperiod Accelerates the Development of Ramie MSLs Mainly in the Reproductive Growth Periods}

The influences of photoperiods on the development of MSLs were studied by growing the MSLs under different photoperiods. It was found that shorter photoperiod evidently accelerated the development rates of the MSLs, especially promoting the reproductive development and shortening the reproductive growth duration (Table 4). Under photoperiods of $9.5-12.5 \mathrm{~h} \cdot \mathrm{d}^{-1}$, the development promotion effect (DA\%) increased as the photoperiod shortened. Besides, the development acceleration of a short photoperiod was much greater in the high temperature season (summer) than in the low temperature season (spring) (Table 4). The results testified a quite high sensitivity to photoperiod of the MSLs and they developed more quickly under shorter photoperiod.

In the summer, the MSLs grew 37-59 days from shoot emergence to pistillate budding under the natural conditions (the controls), while under the short photoperiods (9.5 - $11 \mathrm{~h} \cdot \mathrm{d}^{-1}$ ), the MSLs grew only 18 - 23 days before pistillate budding. The MSLs shortened their basic vegetative growth period and started their reproductive growth earlier under the short photoperiod. Flower bud- ding acceleration under a short photoperiod can be used to scale the photoperiod sensitivity of a plant. The greater the acceleration, the higher the photoperiod sensitivity was. If the acceleration of $60 \%$ is taken as a criterion for dividing the photoperiod sensitivity of the MSLs, then GS13-942 and SS370 are highly sensitive to the photoperiod, and the others are less sensitive (Table 5).

\subsection{Short Photoperiod in Conjunction with High Temperature Accelerates the Development of Ramie MSLs in the Whole Growth Period}

As mentioned above, high temperature (summer treatment) mainly accelerated development in the vegetative growth stage, while the short photoperiod mainly promoted development in the reproductive growth stage. Consequently, it is expected that a short photoperiod in conjunction with a high temperature would accelerate the MSLs development in the whole growth period, resulting in a reduction of the whole growth duration. This was verified by the results in Table 6 .

The MSLs were quite highly sensitive to both temperature and photoperiod. They developed faster and had a shorter whole growth period under the short photoperiod and high temperature conditions (in the summer), and vice versa under the long photoperiod and low temperature (in the spring). Therefore, it may assist of hybridization by treating the ramie MSLs with a short

Table 3. Approximate temperature response indices (TRI) of the MSLs under different photoperiods.

\begin{tabular}{|c|c|c|c|c|c|}
\hline \multirow{2}{*}{ Male sterile line } & \multicolumn{3}{|c|}{ TRI under photoperiods } & \multirow{2}{*}{$\begin{array}{c}\text { Mean } \\
\text { TRI }\end{array}$} & \multirow{2}{*}{$\begin{array}{c}\text { Temperature sen- } \\
\text { sitivity }\end{array}$} \\
\hline & $9.5 \mathrm{~h} \cdot \mathrm{d}^{-1}$ & $11 \mathrm{~h} \cdot \mathrm{d}^{-1}$ & $12.5 \mathrm{~h} \cdot \mathrm{d}^{-1}$ & & \\
\hline GS13-942 & 3.3 & 3.2 & 3.2 & 3.2 & High \\
\hline GS14-1 & 3.0 & 3.2 & 3.1 & 3.1 & High \\
\hline GSA-2 & 3.0 & 2.9 & 2.9 & 2.9 & Moderate \\
\hline GS14-4 & 2.7 & 2.8 & 2.9 & 2.8 & Moderate \\
\hline SS370 & 2.7 & 2.5 & 2.4 & 2.5 & Low \\
\hline GS15-8 & 2.7 & 2.5 & 2.1 & 2.4 & Low \\
\hline
\end{tabular}

Table 4. Effect of photoperiods on ramie MSLs development.

\begin{tabular}{|c|c|c|c|c|c|c|c|c|c|c|}
\hline \multirow{3}{*}{$\begin{array}{l}\text { Growth } \\
\text { period }\end{array}$} & \multicolumn{5}{|c|}{ Treated in the spring } & \multicolumn{5}{|c|}{ Treated in the summer } \\
\hline & \multicolumn{3}{|c|}{ Developmental duration $(\mathrm{d} \pm \mathrm{SD})$} & \multicolumn{2}{|c|}{$\begin{array}{c}\text { DA of short photoperiod } \\
(\%) \dagger\end{array}$} & \multicolumn{3}{|c|}{ Developmental duration $(\mathrm{d} \pm \mathrm{SD})$} & \multicolumn{2}{|c|}{$\begin{array}{c}\text { DA of short photoperiod } \\
(\%) \dagger\end{array}$} \\
\hline & $9.5 \mathrm{~h} \cdot \mathrm{d}^{-1}$ & $11 \mathrm{~h} \cdot \mathrm{d}^{-1}$ & $12.5 \mathrm{~h} \cdot \mathrm{d}^{-1}$ & $9.5 \mathrm{~h} \cdot \mathrm{d}^{-1}$ & $11 \mathrm{~h} \cdot \mathrm{d}^{-1}$ & $9.5 \mathrm{~h} \cdot \mathrm{d}^{-1}$ & $11 \mathrm{~h} \cdot \mathrm{d}^{-1}$ & $12.5 \mathrm{~h} \cdot \mathrm{d}^{-1}$ & $9.5 \mathrm{~h} \cdot \mathrm{d}^{-1}$ & $11 \mathrm{~h} \cdot \mathrm{d}^{-1}$ \\
\hline SE-PB & $39 \pm 0.4$ & $39 \pm 1.0$ & $41 \pm 2.3$ & 3.7 & 3.7 & $21 \pm 1.8$ & $21 \pm 1.8$ & $23 \pm 2.1$ & 9.3 & 8.7 \\
\hline SE-PFB & $59 \pm 3.5$ & $60 \pm 2.6$ & $68 \pm 2.8$ & 13.3 & 12.1 & $38 \pm 3.1$ & $46 \pm 2.6$ & $54 \pm 3.0$ & 29.2 & 14.9 \\
\hline PB-PFB & $19 \pm 2.4$ & $20 \pm 2.0$ & $27 \pm 1.8$ & 27.8 & 24.7 & $17 \pm 1.9$ & $25 \pm 2.0$ & $32 \pm 2.5$ & 45.9 & 22.1 \\
\hline
\end{tabular}

†Compared with $12.5 \mathrm{~h} \cdot \mathrm{d}^{-1}$ photoperiod; DA—Developmental acceleration; SE—Shoot emergence; PB—Pistillate budding; PFB—Pistillate flower blooming. 
Table 5. Photoperiod sensitivities and flower budding acceleration (FBA) of ramie MSLs under short photoperiods (treated in the summer).

\begin{tabular}{|c|c|c|c|c|c|c|c|}
\hline \multirow{2}{*}{$\begin{array}{l}\text { Male sterile } \\
\text { lines }\end{array}$} & \multirow{2}{*}{$\begin{array}{l}\text { Days from SE to PB } \\
\text { for controls } \dagger\end{array}$} & \multicolumn{2}{|c|}{$\begin{array}{c}\text { Under } 9.5 \mathrm{~h} \cdot \mathrm{d}^{-1} \\
\text { photoperiod }\end{array}$} & \multicolumn{2}{|c|}{$\begin{array}{c}\text { Under } 11 \mathrm{~h} \cdot \mathrm{d}^{-1} \\
\text { photoperiod }\end{array}$} & \multirow{2}{*}{$\begin{array}{c}\text { Mean FBA } \\
(\%)\end{array}$} & \multirow{2}{*}{$\begin{array}{c}\text { Photoperiod } \\
\text { sensitivity }\end{array}$} \\
\hline & & $\begin{array}{l}\text { Days from } \\
\mathrm{SE} \text { to } \mathrm{PB} \dagger\end{array}$ & FBA(\%) & $\begin{array}{l}\text { Days from } \\
\mathrm{SE} \text { to } \mathrm{PB} \dagger\end{array}$ & FBA(\%) & & \\
\hline GS13-942 & $51 \pm 3.0$ & $18 \pm 1.0$ & 64.7 & $20 \pm 0.6$ & 60.8 & 62.8 & High \\
\hline SS370 & $59 \pm 3.5$ & $22 \pm 0.4$ & 62.7 & $22 \pm 0.4$ & 62.7 & 62.7 & High \\
\hline GS15-8 & $45 \pm 2.8$ & $22 \pm 0.5$ & 51.1 & $21 \pm 0.9$ & 53.3 & 52.2 & Low \\
\hline GS14-1 & $38 \pm 2.2$ & $20 \pm 0.9$ & 47.7 & $19 \pm 1.0$ & 52.6 & 50.2 & Low \\
\hline GSA-2 & $37 \pm 2.5$ & $20 \pm 0.6$ & 45.9 & $21 \pm 0.6$ & 43.2 & 44.6 & Low \\
\hline GS14-4 & $37 \pm 2.4$ & $23 \pm 1.2$ & 37.8 & $21 \pm 0.5$ & 43.2 & 40.5 & Low \\
\hline
\end{tabular}

SE—shoot emergence; PB—pistillate budding; †Mean \pm SD

Table 6. Combined effects of high temperature and short photoperiod on development of ramie MSLs.

\begin{tabular}{ccccccc}
\hline \multirow{2}{*}{$\begin{array}{c}\text { Growth } \\
\text { period }\end{array}$} & \multicolumn{2}{c}{ Growth duration $(\mathrm{d} \pm \mathrm{SD})$} & \multirow{2}{*}{$\begin{array}{c}\text { DA of SD } \\
\text { and } T_{h}(\%)\end{array}$} & \multicolumn{2}{c}{ DA of $\mathrm{T}_{\mathrm{h}}$ under photoperiods (\% $\left.\pm \mathrm{SD}\right)$} \\
\cline { 2 - 3 } & Under SD and $T_{h}$ & Under LD and $T_{l}$ & & $9.5 \mathrm{~h} \cdot \mathrm{d}^{-1}$ & $11 \mathrm{~h} \cdot \mathrm{d}^{-1}$ & $12.5 \mathrm{~h} \cdot \mathrm{d}^{-1}$ \\
\hline SE-PB & $21 \pm 1.8$ & $41 \pm 2.3$ & 49 & $47 \pm 3.2$ & $46 \pm 2.3$ & $43 \pm 3.0$ \\
SE-PFB & $38 \pm 3.1$ & $68 \pm 2.8$ & 44 & $35 \pm 2.1$ & $23 \pm 2.4$ & $21 \pm 2.5$ \\
PB-PFB & $17 \pm 1.9$ & $27 \pm 1.8$ & 37 & $12 \pm 1.2$ & $-21 \pm 1.5$ & $-17 \pm 1.4$ \\
\hline
\end{tabular}

DA—developmental acceleration; SD—short daylight (9.5 $\mathrm{h} \mathrm{d}^{-1}$ photoperiod); LD—long daylight (12.5 $\mathrm{h} \mathrm{d}^{-1}$ ); $T_{h}$ —high temperature (in the summer); $T_{l}$-low temperature (in the spring); SE—shoot emergence; PB—pistillate budding; PFB—pistillate flower blooming.

photoperiod in different seasons to facilitate cross combinations and avoid of an unexpected pollination. Furthermore, the acceleration effect of a high temperature on ramie MSLs could be decreased, or even cleared away by elongated photoperiod (Table 6).

\subsection{Types of Photo-Temperature Sensitivity of Ramie MSLs}

MSLs are important parents for ramie heterosis utilization, their characteristics of photo-temperature response are therefore important for mating needed cross combinations. The response type of a plant to phototemperature can be determined by the photoperiod and temperature sensitivities, and the basic vegetative growth period. Owing to different response to photoperiod and temperature, the 6 ramie MSLs in this experiment might be classified into 5 types based on the flower budding accelerations of short photoperiod and the approximate temperature response indices (Table 7).

\section{DISCUSSION}

The photo-temperature responses of a crop are of importance both in theory and practice. Understanding these characteristics is helpful, on the one hand, to determine the suitable cultivation areas of the crop for getting high and stable yield. On the other hand, it is good to adjust the flowering time of the cross parents for suc- cessful hybridization, or to stage the cross time of different combinations avoiding of an unexpected pollination.

Ramie cultivars are usually a short-day crop. It has been determined that short photoperiod treatment promotes the development of the ordinary ramie varieties and makes them flower earlier [3,11]. It takes fewer days of short photoperiod to induce ramie flowering under the high temperature seasons (in the summer or early autumn) than under the low temperature seasons (in the spring or early summer) [3]. While different responses of wild species in genus Boehmeria to short photoperiod were observed by Pan et al. [12]. However, it is still necessary to have a systematic study of the photo-temperature responses for ramie varieties, especially for ramie MSLs. In our experiment, we confirmed that the tested ramie MSLs are sensitive to the temperature and photoperiod by growing the MSLs under different photoperiods and different season (temperature) conditions. The short photoperiod and high temperature (in the summer) can evidently decrease the growth period and make the MSLs flower earlier. But the acceleration effect of high temperature can be minimized, or even cleared away by long photoperiod.

The effects of photoperiod and temperature on ramie development are complex. In this experiment, due to lack of the staminate flowers in some of the tested MSLs, the female reproductive organs were recorded as a coin 
Table 7. Response type of ramie MSLs to photoperiod-temperature.

\begin{tabular}{|c|c|c|c|c|}
\hline Type & $\begin{array}{l}\text { Response sensitivity to photope- } \\
\text { riod-temperature }\end{array}$ & $\begin{array}{l}\text { FBA of short photo- } \\
\text { period } \dagger\end{array}$ & Temperature response index $\ddagger$ & Representative MSLs \\
\hline 1 & $\begin{array}{l}\text { High sensitivity to both photoperiod and } \\
\text { temperature }\end{array}$ & $\geqslant 60 \%$ & $>3.0$ & GS13-942 \\
\hline 2 & $\begin{array}{c}\text { Sensitivity high to photoperiod and low } \\
\text { to temperature }\end{array}$ & $\geqslant 60 \%$ & $\leqslant 2.5$ & SS370 \\
\hline 3 & $\begin{array}{c}\text { Sensitivity low to photoperiod and high } \\
\text { to temperature }\end{array}$ & $<60 \%$ & $>3.0$ & GS14-1 \\
\hline 4 & $\begin{array}{l}\text { Sensitivity low to photoperiod and mod- } \\
\text { erate to temperature }\end{array}$ & $<60 \%$ & $2.6 \sim 3.0$ & GS14-4, GSA-2 \\
\hline 5 & $\begin{array}{l}\text { Low sensitivity to both photoperiod and } \\
\text { temperature }\end{array}$ & $<60 \%$ & $\leqslant 2.5$ & GS15-8 \\
\hline
\end{tabular}

$†$ Represents the photoperiod sensitivity; $\ddagger$ Represents the temperature sensitivity; FBA—Flower budding acceleration.

cident indicator for observation, but the effects of temon the development of the male reproductive organs of the MSLs were neglected. In fact, in some experiments it was observed that the environmental temperature could change the pollen fertility of some rape male sterile lines $[13,14]$. This was considered as a result of the combined effect of the environmental temperature and the nutrition status in the MSLs [14]. In our experiment we also found a yearly difference in the development of the staminate flower buds in some MSL, and the bigger and higher plants had somehow better developed staminate flower buds. Are there interactive effects of the environmental temperature and the nutrition status on the expression of fertility in the ramie MSLs, and on the temperature-sensitive response? This is a new problem to approach. Besides temperature and photoperiod, it is worthwhile to investigate the effects of changes in sunlight intensity, wavelength and humidity from spring to summer on the development of ramie MSLs.

\section{CONCLUSIONS}

The conclusion was derived by summarizing the developmental response to photoperiod and temperature of six male sterile lines (MSLs) of ramie in the study. The MSLs showed different development rates in the reproductive growth stage under the conditions of higher temperature and short photoperiod, but a stable vegetative growth duration. On the other hand, higher temperature accelerated vegetative growth, while the short photoperiod treatment accelerated the reproductive growth of the MSLs. The short photoperiod treatment combined with higher temperature obviously accelerated both the vegetative and reproductive growth of the MSLs. But the effect of higher temperature decreased, or even disappeared along with the photoperiod elongation. Five photo-temperature response types were constituted based on the flower budding acceleration of short photoperiod and the approximate temperature response index of the MSLs. The results would provide guidance for determining cross combinations, assist with the breeding of new cultivars and assist with ramie seed production.

\section{ACKNOWLEDGEMENTS}

The authors are grateful to the National Natural Science Foundation of China (Project No 30360058, Project No 30971825) for financial support to this study.

\section{REFERENCES}

[1] Kaul, M.L.H. (1988) Male sterility in higher plants. Springer-Verlag Berlin Heidelberg, New York, 221-232.

[2] Qin, T.C. (1993) Crop breeding by using male sterility. Chinese Agricultural Press, Beijing.

[3] Li, Z.D. (1989) Ramie physiology, bio-chemistry, genetics and breeding. Chinese Agricultural Press, Beijing, 158-167.

[4] Liang, X.N., Zhang, S.W. and Xiao., D.X. (1998) Studies on ramie parthenogenesis and pure line creation. Agricultural Modernization Research, 19, 91-94.

[5] Liu, F.H. and Liang, X.N. (2000) Preliminary study on biochemical and physiological traits of ramie male sterile lines. China's Fiber Crops, 22, 16-20.

[6] Song, J., Zhang, Z.H. and Pan, G.T. (2007) Physiological and biochemical characteristics in ramie male sterile lines. Journal of Tropical and Subtropical Botany, 15, 423-428.

[7] Zhang, Z.H., Wei, G., Xu, J.J., Zhao, S.Y., Yang, Y. and Qiu, Y.B. (2003) Report on breeding of a new hybrid ramie combination 'Chuanzhu 8' with good quality and high yield. China's Fiber and Products, 25, 168-171.

[8] Zhang, Z.H., Wei, G., Yang, Y. and Shu, Z.X. (2005) Breeding and utilization of ramie male sterility line 'C26'”. Plant Fibers and Products, 27, 109-112.

[9] Diao, C.Q., (1994) Cultivation of field crops (Southern version). Chinese Agricultural Press, Beijing, 47-57.

[10] Deng, L.Q. (1987) Study on photo-temperature responses of kenaf varieties. Scientia Agricultura Sinica, 20, 56-62.

[11] Li, Z.D. (1980) The theory and techniques of fiber crops. Shanghai Science and Technology Press, Shanghai, 99-110.

[12] Pan, Q.H., Lai, Z.J. and Ouyang, A.P. (2005) Preliminary study on the day-length and temperature characteristics of wild-type ramie. China's Fiber and Products, 27, 286-291.

[13] Yang, G.S. and Fu, T.D. (1987) Effect of environments on 
rape cytoplasmic male sterile lines. China's Oil Crops, 3 15-19.

[14] Li, J.N., Tang, Z.L. and Chen, L. (1995) Effects of temperature on the fertility change stage and critical pa- rameters of rape male sterile line with Polima cytoplasm. Journal of Southwest Agricultural University, 17, 391394. 